\title{
GOSTO DE SEDIÇÃO: SÉRGIO BUARQUE DE HOLANDA, MANUEL BANDEIRA E A AUTORIA DAS CARTAS CHILENAS*
}

\author{
Thiago Lima Nicodemo** \\ Pós-graduando em História Social - FFLCH/USP
}

\begin{abstract}
Resumo
Este artigo propõe uma reflexão sobre a relação entre história e crítica literária na obra de Sérgio Buarque de Holanda da década de 1940, por meio da análise do debate sobre a autoria das Cartas Chilenas. Dentre os envolvidos no debate, procura-se destacar a interlocução entre Sérgio Buarque e o poeta Manuel Bandeira. Mesmo ligados profissionalmente a instituições culturais estatais, é possível identificar em seus argumentos uma postura crítica em relação às diretrizes culturais de construção de identidade nacional operadas pelo Estado brasileiro durante o período do Estado Novo (1937-1945).
\end{abstract}

\section{Pallavras-Chave}

Sérgio Buarque de Holanda (1902-1982) • Manuel Bandeira (1886-1967) • Historiografia Brasileira • História da Crítica Literária no Brasil

\section{Abstract}

This article investigates some aspects of the relations between history and literary criticism in Sergio Buarque de Holanda's writings of the 1940s. It analyzes Sergio Buarque's participation in the debate on the authorship of the Cartas Chilenas, specifically through his discussions with the poet Manuel Bandeira. Despite the fact that they were professionally connected to official cultural institutions, it is possible to identify both authors' critical view regarding the cultural guidelines adopted by the Brazilian State in the construction of a national identity throughout the period known as Estado Novo (1937-1945).

\section{Keywords}

Sérgio Buarque de Holanda (1902-1982) • Manuel Bandeira (1886- 1967) • Brazilian Historiography $\bullet$ History of Brazilian Literary Criticism

\footnotetext{
* Dedico este artigo a Christina Rostworowski da Costa e a Paulo Iumatti pelo apoio incessante. Além deles, agradeço aos professores Raquel Glezer, João Adolfo Hansen e Tania Regina de Luca pela leitura e comentários.

** Bolsista CAPES.
} 
Além de marco da historiografia brasileira dos anos $1930^{1}$, o livro Raízes do $\mathrm{Brasil}^{2}$ é uma espécie de paradigma nas análises sobre a obra de seu autor, Sérgio Buarque de Holanda. Muitos dos temas estudados neste que foi seu primeiro livro, publicado em 1936, são desenvolvidos nas outras obras que produziu até poucos anos antes de falecer em 1982. Por outro lado, o percurso intelectual de Sérgio Buarque de Holanda é pautado por uma série de mudanças, algumas das mais relevantes ocorridas nos anos imediatamente consecutivos à publicação de Raízes do Brasil. A comparação entre este livro e sua segunda obra publicada, Monções ${ }^{3}$, em 1945, pode ajudar a tornar perceptível algumas destas mudanças.

Uma diferença que salta aos olhos, mesmo em uma leitura inicial, é o encaminhamento do tema central de cada livro. Raízes do Brasil configura-se em uma interpretação abrangente de características da formação histórica nacional que dificultam o processo de modernização brasileiro. O segundo é um estudo circunscrito do processo de expansão e colonização do interior do território que viria a ser o brasileiro, por meio da reconstituição histórica do caminho fluvial do Rio Tietê à região de Cuiabá.

Outra diferença bastante sensível reside no método utilizado nos livros. Raízes do Brasil é desenvolvido através da elaboração de modelos interpretativos, como por exemplo o do "homem cordial", ou de dualidades como a do "ladrilhador" e do "semeador". A existência destes modelos garante a clareza da argumentação, dada a pretensão de abarcar como tema do livro a história de adaptação do europeu a um novo mundo ${ }^{4}$.

\footnotetext{
${ }^{1}$ Segundo idéia esboçada por Antonio Candido no prefácio à $4^{\mathrm{a}}$ ed. de Raízes do Brasil, publicada em 1963 e expressa de forma definitiva na introdução que o mesmo autor escreveu em 1967, para a edição seguinte de Raízes em 1969. Este texto consta nas versões mais atuais de Raízes das quais a mais recente é a 26a , publicada em 1995. CANDIDO, Antonio. Prefácio. In: HOLANDA, Sérgio Buarque de. Raízes do Brasil. 4ª ed. Brasília: Editora Universidade de Brasília, 1963, p. IX; CANDIDO, Antonio. O significado de "Raízes do Brasil". In: HOLANDA, Sérgio Buarque de. Raízes do Brasil. Rio de Janeiro: José Olympio, 1969 e CANDIDO, Antonio. O significado de "Raízes do Brasil". In: HOLANDA, Sérgio Buarque de. Raízes do Brasil. 26 ed. São Paulo: Cia. das Letras, 1995, p. 9-12.

${ }^{2}$ HOLANDA, Sérgio Buarque de. Raízes do Brasil. $1^{\mathrm{a}}$ ed. Rio de Janeiro: José Olympio, 1936. ${ }^{3}$ HOLANDA, Sérgio Buarque de. Monções. $1^{\mathrm{a}}$ ed. Rio de Janeiro: Casa do estudante do Brasil, 1945.

${ }^{4}$ MONTEIRO, Pedro Meira. A queda do aventureiro. Aventura, cordialidade e os novos tempos em Raízes do Brasil. Campinas: Editora da Unicamp, 1999, p. 47.
} 
Em contrapartida, Monções é desenvolvido através de um método fluido, preocupado em escapar de generalizações e em captar as diversas temporalidades dos eventos. Sua análise das populações ligadas ao comércio e à expansão fluvial vai desde a cultura material até seu universo mental, sociabilidade, costumes e ritos 5 .

Poucos trabalhos acadêmicos publicados sobre a obra de Sérgio Buarque levam em consideração e sugerem interpretações sobre as mudanças ocorridas nestes anos. Dentre estas obras se destaca o estudo de Maria Odila L. S. Dias, concebido como introdução a uma coletânea de textos de Sérgio Buarque de Holanda publicada em 1985 na coleção 'Grandes Cientistas Sociais' da editora Ática ${ }^{6}$. Este texto permanece como a interpretação mais abrangente de sua obra e, muito provavelmente, foi o primeiro a problematizar as diferenças entre Raízes do Brasil e Monções. Como escreveu a historiadora sobre o período compreendido entre a publicação dos livros Monções e Caminhos e fronteiras:

"Estes são os livros representativos da primeira fase de pesquisa sistemática das fontes na obra histórica de Sérgio Buarque de Holanda e de consolidação de um estilo narrativo muito pessoal de interpretação e reconstituição do passado. Coincidiram com sua mudança para São Paulo, com suas atividades de professor na Escola de Sociologia e Política e com seu trabalho na direção do Museu Paulista."

Assim, pode-se dizer que durante o período entre a publicação de Raízes do Brasil e de Moções, isto é, entre finais dos anos 1930 e a primeira metade dos anos 1940, o autor desenvolveu um estilo e um método que permitem considerá-lo um historiador propriamente dito aos olhos de um crítico contemporâneo. O trecho destacado acima fundamenta esta hipótese na medida em que aponta ao início de uma fase "de pesquisa sistemática das fontes" na obra histórica de Sérgio Buarque. O desenvolvimento deste método explica em boa

\footnotetext{
${ }^{5}$ DIAS, Maria Odila Leite da Silva. Sérgio Buarque de Holanda, historiador. In: HOLANDA, Sérgio Buarque de. Sérgio Buarque de Holanda. Organização de Maria Odila L. S. Dias. São Paulo: Ática, 1985. (Coleção Grandes Cientistas Sociais, n. 51), p. 25-26.

${ }^{6}$ DIAS, Maria Odila Leite da Silva. Sérgio Buarque de Holanda, historiador ..., op. cit, p. 5-64.

${ }^{7}$ Idem, p. 25.
} 
medida as diferenças significativas na forma e no conteúdo entre Raízes do Brasil e Monções.

Para compreender melhor este amadurecimento técnico e estilístico ao qual se refere Maria Odila L. S. Dias, deve-se atentar às atividades empreendidas por Sérgio Buarque neste período, seja na suas experiências profissionais, em sua produção intelectual ou mesmo em seu convívio social. Parte desta pesquisa foi recentemente concluída em tese de douramento de autoria de Marcus Vinicius C. Carvalho, que aponta a importância das atividades profissionais e sociais no amadurecimento de seu método crítico ${ }^{8}$.

Dentre estas atividades, merecem destaque algumas como a docência na então recém criada Universidade do Distrito Federal, na qual foi convidado a participar logo após a publicação de seu livro de estréia. Nesta Universidade foi professor assistente nas cátedras de História Moderna e Econômica e de Literatura Comparada, cujos responsáveis eram respectivamente Henri Hauser e Henri Trouchon ${ }^{9}$. O próprio autor, muitos anos depois, escreveu sobre o papel importante que teve Hauser na sua formação como historiador. Ao se referir ao papel crescente dos estudos históricos em sua carreira após sua volta da Alemanha no início dos anos 1930, Sérgio Buarque comenta:

"Estudos que havia apurado depois no Rio de Janeiro, durante estreito
convívio que ali mantive com Henri Hauser, um dos mais notáveis histo-
riadores de seu tempo, vindo da Sorbonne na leva dos 16 professores
convidados a ir lecionar na efêmera Universidade do Distrito Federal
por iniciativa de Anísio Teixeira, organizador e primeiro reitor do esta-
belecimento. Esse convívio, somado às obrigações que me competiam,

${ }^{8}$ CARVALHO, Marcus Vinicius Corrêa. Outros lados: Sérgio Buarque de Holanda, critica literária, história e política. Campinas (SP), 2003. Tese de Doutoramento. Instituto de Filosofia e Ciências Humanas da Unicamp. Em especial a terceira parte: 'Sérgio Buarque de Holanda e as instituições de cultura letrada'. Sobre a obra de Sérgio Buarque de Holanda neste período também merece destaque o trabalho A conquista do oeste, cuja análise concentra-se fundamentalmente nos livros Monções e Caminhos e Fronteiras a partir da consideração de que o processo de elaboração destes livros fez parte de uma unidade de interesses desenvolvida ao longo dos anos 1940. WEGNER, Robert. A conquista do oeste. A fronteira na obra de Sérgio Buarque de Holanda. Belo Horizonte: Editora UFMG, 2000.

${ }^{9}$ CARVALHO, Marcus Vinicius Corrêa. Outros lados... op. cit., p. 181-182. 
de assistente junto à cadeira de História Moderna e Econômica, sob a responsabilidade de Hauser, me haviam forçado a melhor arrumar, ampliando-os consideravelmente, meus conhecimentos nesse setor, e tentar aplicar os critérios aprendidos ao campo dos estudos brasileiros, a que sempre me havia devotado, ainda que com uma curiosidade dispersiva e mal educada" ${ }^{10}$.

Ainda na Universidade, Sérgio Buarque estreitou relações com colegas docentes com os quais já vinha convivendo há anos, como Manuel Bandeira, com o qual havia criado laços de amizade desde sua mudança para o Rio de Janeiro em 1920, Gilberto Freyre, com o qual estreitou relações ao longo dos anos 1930 no círculo de intelectuais ligados à Livraria José Olympio ${ }^{11}$, Luís Camilo de Oliveira Neto, diretor de unidade e reitor da mesma instituição ${ }^{12}$, entre outros.

Extinta a Universidade do Distrito Federal em 1939, Sérgio Buarque iniciou seus trabalhos no Instituto Nacional do Livro, no qual foi chefe da Seção de Publicações até $1944^{13}$. Neste mesmo ano foi convidado para chefiar a Divisão de Consultas da Biblioteca Nacional, cargo que ocupou até mudar-se para São Paulo, em 1946.

Ademais, não se pode perder de vista a sua extensa contribuição como crítico literário, especialmente desde o início da década de 1940, momento no qual intensifica suas atividades em rodapés de jornais como o Diário de Notícias e o Diário Carioca, ambos do Rio de Janeiro. Sua contribuição em artigos de jornal é material importante na análise da formação de seu método crítico.

\footnotetext{
${ }^{10}$ HOLANDA, Sérgio Buarque de. Tentativas de Mitologia. São Paulo: Perspectiva, 1979, p. 14.

${ }^{11}$ Apesar de enfocar principalmente os romancistas e sua produção, sobre a questão dos círculos de sociabilidade ligados ao ambiente da livraria José Olympio, ver: SORÁ, Gustavo. Brasilianas. A Casa José Olympio e a instituição do livro nacional. Rio Janeiro (RJ), 1998. Tese de Doutoramento em Antropologia Social - Departamento de Ciências Sociais, Universidade Federal do Rio de Janeiro.

${ }^{12}$ BARBOSA, Francisco de Assis. Prefácio. OLIVEIRA NETO, Luís Camilo de. História, Cultura e Liberdade, Rio de Janeiro: José Olympio, 1975, p. XII. Nos textos que consultei, a grafia do nome 'Luís Camilo de Oliveira Neto' aparece também como 'Luís Camillo de Oliveira Netto'. Neste artigo, opto pela primeira forma, a mesma utilizada por Sérgio Buarque em seus textos.

${ }^{13}$ CARVALHO, Marcus Vinicius Corrêa. Outros lados... op. cit., p. 221.
} 
Intelectuais como Antonio Candido e Antonio Arnoni Prado vêm apontando, pelo menos desde o início da década de 1990, à necessidade de uma avaliação conjunta da produção de crítica literária e história na obra de Sérgio Buarque de Holanda ${ }^{14}$. Esta análise permitiria aprofundar o estudo da constituição do método crítico buarqueno, uma vez que este processo é contemporâneo ao período mais intenso de sua atividade como crítico literário, que ocorreu entre aproximadamente 1941 e 1952.

Neste artigo pretendo analisar alguns aspectos do percurso intelectual de Sérgio Buarque de Holanda no período posterior à publicação de Raízes do Brasil, isto é, entre a segunda metade dos anos 1930 e a primeira metade dos anos 1940. Mais especificamente, meu objetivo é investigar os meios e as razões do desenvolvimento de um método crítico de investigação histórica na obra de Sérgio Buarque deste período, enfocando o diálogo entre sua produção de crítica literária e de história. Para isto, concentrarei minha análise em seus textos que tratam da polêmica da autoria das Cartas Chilenas, escritos entre 1939 e 1941, principalmente nas páginas da Revista do Brasil. Estes textos correspondem à sua participação em um debate que também envolveu intelectuais como Manuel Bandeira, Luís Camilo de Oliveira Neto e Afonso Arinos de Melo Franco.

Dedicarei mais atenção à parte do debate referente à discussão entre Sérgio Buarque e o poeta Manuel Bandeira, uma vez que nela encontrei uma interlocução mais intensa no sentido da constituição de métodos com traços em comum. Nos textos escritos pelos dois intelectuais, é possível identificar uma tentativa de introdução de novos instrumentos de análise textual a serviço de ideais políticos libertários. É através da análise destas relações que pretendo mostrar como elementos da crítica literária buarquena do início dos anos 1940 contribuíram na definição de um método peculiar de investigação histórica em uma fase de sua obra posterior à publicação de Raízes do Brasil.

${ }^{14}$ Cf. CANDIDO, Antonio. Introdução. In: HOLANDA, Sérgio Buarque. Capítulos de literatura colonial. São Paulo: Brasilense, 1991, p. 11; PRADO, Antonio Arnoni. Nota sobre a edição. In: HOLANDA, Sérgio Buarque de. O Espírito e a Letra. Estudos de crítica literária. v. 1. São Paulo: Cia. das Letras, 1996, p. 16-18. 


\section{A entrada de Sérgio Buarque de Holanda no debate}

$\mathrm{Na}$ série de artigos que escreveu em janeiro e fevereiro de $1941^{15}$, Sérgio Buarque de Holanda comentou as novas propostas e pontos de vista que um poeta, Manuel Bandeira, um historiador, Luiz Camilo de Oliveira Neto, e um crítico e historiador, Afonso Arinos de Melo Franco, haviam aventado em trabalhos recentes sobre a questão da autoria das Cartas Chilenas. Segundo Sérgio Buarque, o que existiria em comum netas perspectivas tão distintas é que os três estudos chegaram a um parecer comum: as Cartas Chilenas eram de autoria de Tomás Antonio Gonzaga ${ }^{16}$.

Segundo o autor, o trabalho do poeta Manuel Bandeira, que atribuía a autoria das Cartas Chilenas a Tomás A. Gonzaga, se constituía em iniciativa modelar nas investigações do gênero. O poeta propôs em seu trabalho que se interrompessem as explicações da obra através do percurso pessoal do suposto autor, e que a análise se concentrasse em questões poéticas e de linguagem. Sobre estas questões poderiam ser feitos dois tipos de consideração: as que se concentrassem nas análises da estrutura íntima do verso, como estrofação e rimas; e análises que levassem em consideração, eminentemente, a linguagem como peculiaridade de vocabulário e sintaxe.

Manuel Bandeira decidiu abandonar a possibilidade de analisar as Cartas Chilenas através da estrutura dos versos. Elas haviam sido escritas em versos decassílabos brancos, forma que tem incidência raríssima nas obras dos dois principais autores aos quais poderiam ser atribuídas - Cláudio Manuel da Costa e Tomas A. Gonzaga. Por isso, tornava-se impossível identificar quem seria o autor pela incidência destes recursos em outras obras dos dois principais suspeitos. Restou-lhe, segundo Sérgio Buarque, concentrar sua análise na prova de estilo, ou seja, na identificação dos usos de vocabulário e sintaxe entre as Cartas Chilenas e outras obras dos dois poetas ${ }^{17}$.

\footnotetext{
${ }^{15}$ HOLANDA, Sérgio Buarque de. 'As Cartas Chilenas', Diário de Notícias, Rio de Janeiro, 26 de janeiro de 1941, seção 3, p. 13-14; e 'Ainda as Cartas Chilenas', Diário de Notícias, Rio de Janeiro, 02 de fevereiro de 1941, seção 3, p. 13-14. Estes artigos foram republicados no livro Tentativas de mitologia. São Paulo: Perspectiva, 1978, sob o título de 'As Cartas Chilenas', com pouquíssimas alterações em relação aos artigos originais. Utilizarei a partir daqui a versão em livro como referência por ser de mais fácil acesso ao leitor.

${ }^{16}$ HOLANDA, Sérgio Buarque de. Tentativas de mitologia, op. cit., p. 222.

${ }^{17}$ Idem. p. 222.
} 
Sérgio Buarque também comentou o trabalho de Luiz Camilo de Oliveira Neto, cujos méritos residiam principalmente no rigor da pesquisa histórica e no uso de documentos até então inéditos. Dentre eles, merece destaque particular o ofício dirigido à Rainha, assinado pelo ouvidor de Vila Rica, Tomas A. Gonzaga, em que constam denúncias ao Governador D. Luís da Cunha Meneses, muito semelhantes àquelas das Cartas Chilenas, incluindo, às vezes, o uso de termos idênticos. O crítico deixou de tecer mais comentários sobre o trabalho de Luís Camilo, uma vez que não dispunha da totalidade de seu trabalho - um conjunto de artigos esparsos publicados em jornal ${ }^{18}$.

Sobre o trabalho de Afonso Arinos de Melo Franco, Sérgio Buarque ressaltou que sua principal qualidade era a capacidade de congregar as características das iniciativas tanto de Luis Camilo quanto de Manuel Bandeira: o rigor da investigação histórica e a sensibilidade para as nuanças da linguagem. O trabalho de Afonso Arinos vinha na circunstância de prefácio a uma edição crítica das Cartas Chilenas, realizada pelo mesmo autor e encomendada pelo Ministério da Educação e Saúde ${ }^{19}$.

Os comentários de Sérgio Buarque fazem crer que ele estava de acordo com as posições e formas de argumentação dos três autores e ademais as considerava complementares. No entanto, se havia apenas concordância entre as opiniões, por que dedicar tanta atenção a um tema tão visitado como a autoria das Cartas Chilenas? Possivelmente, esta concordância é um indício da coesão de um grupo, o que leva a supor a existência de outros grupos e de outras opiniões. Para compreender os significados da discussão nos anos 1940, faz-se necessário analisar alguns aspectos da historiografia e da tradição em torno das Cartas Chilenas, o que farei no próximo item deste artigo.

Antes disso, devo dizer que o próprio Sérgio Buarque, ainda no mesmo artigo, fornece uma pista que permite encaminhar a investigação sobre os significados históricos da discussão sobre a autoria das Cartas Chilenas. Segundo o crítico, a tradição que remonta ao próprio momento histórico de circulação das Cartas Chilenas apontava Gonzaga como seu autor. Esta tradição só teria

\footnotetext{
${ }^{18}$ Vale ressaltar que a série de artigos referida por Sérgio Buarque, de autoria de Luís Camilo de Oliveira Neto, foi publicada em O Jornal entre 24 de dezembro de 1939 e 28 de janeiro de 1940 e totalizam seis artigos que foram também publicados postumamente no livro História, cultura e liberdade, op. cit.

${ }^{19}$ Afonso Arinos contribuiu para a polêmica na própria Revista do Brasil, publicando o texto "A autoria das "Cartas Chilenas"' na edição da revista de número 28, de outubro de 1940.
} 
sido questionada de modo significativo em dois momentos distintos pelo mesmo indivíduo, o historiador Francisco Adolfo de Varnhagen. O primeiro momento foi em 1851, quando atribuiu a autoria das Cartas a Alvarenga Peixoto e, em 1867, quando, mudando de idéia, atribuiu-à Cláudio Manuel da $\operatorname{Costa}^{20}$. A seguir reproduzo um trecho no qual Sérgio Buarque comenta, com irreverência, as posições de Varnhagen:

"Com o estudo e a meditação, o visconde teve a coragem de corrigir por duas vezes sua opinião quanto ao nome do autor das Cartas. Não quanto ao ponto onde contraria uma tradição aparentemente bem assente, a tradição de que o poema era da autoria de Gonzaga. Nisso reconhecemos ainda uma vez o perfil traçado por Capistrano de Abreu daquele homem caturra, que em tudo expunha complacentemente sua opinião, com tanto mais complacência quanto se afastava da opinião comum." ${ }^{21}$

Não é apenas devido aos absurdos da argumentação de Varnhagem que Sérgio Buarque faz questão de demonstrar tanto descontentamento. O crítico deixa em suspenso, nas entrelinhas, a resposta para uma pergunta quase que necessária no encadeamento de sua argumentação. Por que justamente um historiador como Varnhagem precisou romper com a tradição de atribuição de autoria das Cartas a Gonzaga, tantos anos depois de sua composição e circulação?

\section{As Cartas Chilenas e a construção da identidade nacional}

As Cartas Chilenas são um conjunto de versos satíricos compostos em decassílabos brancos, divididos em treze cartas encontradas e traduzidas por um provável pseudônimo - Critilo - que as enviou de Santiago do Chile para seu amigo Doroteu na Espanha. A sátira tem como objeto as arbitrariedades realizadas pelo governador do Chile, o Fanfarrão Minésio ${ }^{22}$.

\footnotetext{
${ }^{20}$ Sérgio Buarque comentou também sobre uma terceira versão, anterior às duas primeiras. Em 1847, no livro Épicos Brasileiros, Varnhagen formulou a mais extravagante das três hipóteses: as Cartas eram uma sátira ao Conde de Bobadela, escritas por Domingos Caladas Barbosa. Sérgio acrescentou após a referência ao suposto autor e à suposta vítima da sátira um ponto de exclamação, ressaltando comicamente o absurdo da hipótese. HOLANDA, Sérgio Buarque de. Tentativas de mitologia, op. cit., p. 225.

${ }^{21}$ HOLANDA, Sérgio Buarque de. Tentativas de mitologia, op. cit., p. 225.

${ }^{22}$ FURTADO, Joaci Pereira (org.). Introdução. In: GONZAGA, Tomás Antônio. Cartas Chilenas. São Paulo: Cia. Das Letras, 1995, p. 9.
} 
É ponto pacífico que o satirizado é, na realidade, D. Luís da Cunha Meneses, governador da capitania de Minas Gerais entre 1783 e 1788. E que Chile e Espanha são na verdade metáforas para Brasil e Portugal, o que pode ser percebido através da exploração satírica das categorias metrópole e colônia.

A festa narrada nas cartas 5 e 6 muito provavelmente faz referência ao casamento do príncipe português com D. Carlota Joaquina, em 1786. Isto indica que o poema foi produzido entre esta data e 1789, quando a Inconfidência Mineira foi descoberta e dissolvida, e seus colaboradores e cúmplices foram presos. Dentre os punidos estavam Cláudio Manuel da Costa, Alvarenga Peixoto e Tomás A. Gonzaga - os mais prováveis autores do poema.

Para avaliar o quanto as Cartas Chilenas e a questão de sua autoria se tornaram objeto relevante de discussões acaloradas e debates históricos, é necessário irmos à historiografia do movimento que ficou conhecido como Inconfidência Mineira $^{23}$. Inicialmente, devo ressaltar que as Cartas Chilenas passaram a participar mais freqüentemente da cena intelectual e literária nacional apenas depois da independência do Brasil ${ }^{24}$. Este reaparecimento das Cartas ao longo das primeiras décadas que se sucederam à independência culmina com sua primeira edição no ano de 1845, mais de meio século depois de sua produção. Esta edição foi feita por Santiago Nunes Ribeiro e publicada na revista Minerva Brasiliense ${ }^{25}$.

A apropriação das Cartas Chilenas no cenário literário do Império nascente operaram no sentido de lhe conferir uma condição de registro de uma realidade histórica passada. Segundo Joaci Pereira Furtado:

"O credenciamento da sátira mineira como registro histórico, açodado por seu caráter deliberadamente testemunhal e de crítica com base em uma realidade que trata com minúcias, é passo essencial para lhe garantir a autoridade que os leitores buscarão no texto afim de legitimar suas depreensões. Contudo, a confiabilidade da narrativa de Critilo não é mediada pela análise da perspectiva histórica assumida pelo poeta,

\footnotetext{
${ }^{23}$ Para uma análise da historiografia sobre as Cartas Chilenas: FURTADO, Joaci Pereira. Uma república de leitores: história e memória na recepção das Cartas Chilenas (18451989). São Paulo: Hucitec, 1997.

${ }^{24}$ FURTADO, Joaci Pereira. Uma república... op. cit. Para um panorama das discussões sobre as Cartas durante o Império ver o capítulo 3 - 'Retrato'.

${ }^{25}$ Idem, p. 41.
} 
mas por um olhar remissivo preocupado em rastrear a gestação da conjura ou da consciência nacional" ${ }^{\prime 26}$.

A formação da historiografia comprometida com a construção da identidade nacional brasileira condiciona um olhar sobre as Cartas que as considera não mais apenas artefato literário, mas também prova da existência histórica de uma vontade de emancipação nacional anterior à formação de um Estado brasileiro independente de Portugal.

A construção da identidade nacional brasileira foi promovida de modo deliberado pelo recém formado Estado brasileiro de diversas formas. Uma das mais significativas foi o patrocínio e cooptação de intelectuais e artistas, e a criação de órgãos que tiveram as tarefas de construir uma memória nacional. O Instituto Histórico e Geográfico Brasileiro, fundado em $1838^{27}$, foi uma das instituições importantes na realização desta tarefa. Dentre seus membros, merece destaque a atuação de Francisco Adolfo de Varnhagen. A sua obra mais conhecida, História Geral do Brasil, publicada em 1857, pode ser considerada, em muitos aspectos, a realização de uma das etapas do projeto de construção de uma identidade nacional brasileira ${ }^{28}$.

No desenvolvimento da historiografia brasileira comprometida com os ideais e necessidades da nação, a Inconfidência Mineira, na condição de tentativa de insurreição contra o domínio português, pelo menos em Vila Rica, adquiriu a condição de movimento de libertação nacional do jugo lusitano. O Brasil, unidade política e ideológica presente apenas na mente destes homens do século XIX e XX, ganha uma anterioridade absoluta - fundamento metafísico de sua própria unidade e existência como nação. A Inconfidência Mineira passa a ser um dos marcos da luta desta nação para se tornar independente, um dos seus grandes símbolos.

\footnotetext{
${ }^{26}$ Idem, p. 91.

${ }^{27}$ GUIMARÃES, Manoel Luís Salgado. Nação e civilização nos trópicos: O instituto histórico e geográfico brasileiro e o projeto de uma história nacional, Estudos Históricos, Rio de Janeiro, n. 1, 1988, p. 5-7.

${ }^{28}$ WEHLING, Arno. Estado, história e memória. Varnhagen e a construção da identidade nacional. Rio de Janeiro: Nova Fronteira, 1999. Particularmente o cap. 1: "Os anos formativos, conjuntura, memória, história”.
} 
Do mesmo modo, a imagem dos envolvidos na Inconfidência, mesmo tratando-se de coadjuvantes ou simples cúmplices, foi sendo construída, transformando estes personagens em verdadeiros heróis, homens que sacrificaram suas vidas pelo ideal da nação. Como alguns destes inconfidentes, antes de se envolverem com o movimento, participaram de um movimento literário conhecido como arcadismo, só se poderia esperar que esta atividade literária guardasse relações diretas com a Inconfidência.

As Cartas Chilenas, na condição de sátira a um governo português em território americano, tornaram-se, assim, um dos grandes símbolos dessa luta de libertação da nação por intermédio de seus grandes heróis. Não é de se surpreender que desde meados do século XIX a identidade do autor das Cartas tenha sido motivo de tão acaloradas discussões, pois, uma vez revelado, seu autor mereceria posição de destaque no panteão dos heróis nacionais.

Assim, o primeiro caminho da historiografia comprometida com os ideais nacionais na interpretação das Cartas Chilenas foi o de transformá-la em porta voz direto e objetivo dos ideais da Inconfidência Mineira. A imagem deste movimento foi, por sua vez, devidamente distorcida - de revolta contra as autoridades locais de modo bastante circunscrito para movimento precursor, prenúncio da libertação de uma nação já constituída.

Outra providência tomada no mesmo sentido diz respeito à questão da autoria das Cartas Chilenas. A nacionalidade portuguesa de seu mais provável autor, Tomás A. Gonzaga, seus laços de fidelidade com a coroa e suas tendências reformistas absolutistas criavam um impasse aos historiadores comprometidos com a construção da nação, o que se desdobrava em duas alternativas: ou negar que Tomás A. Gonzaga pudesse ser o autor das Cartas, como fez Varnhagen, ou criar um novo autor - um outro Tomás A. Gonzaga, um herói profundamente comprometido com os ideais da nova nação e disposto a arriscar sua vida pela emancipação do Estado.

E o debate sobre as Cartas Chilenas continuou como um longo e importante capítulo da historiografia da Inconfidência Mineira. Do mesmo modo, o processo de construção dos heróis da Inconfidência continuou determinando as opiniões sobre os possíveis autores das Cartas. Este processo se intensificou cada vez mais em um período que se inicia em finais do século XIX, principalmente durante a República Velha, e vai até a primeira metade do século XX, especialmente durante o período conhecido como Estado Novo. Durante este período, cada vez mais a Inconfidência Mineira e as Cartas Chilenas foram sendo revestidas de uma aura de mito fundador da nação ${ }^{29}$. 


\section{A crítica de Sérgio Buarque às interpretações das Cartas Chilenas}

Depois de atribuir a Varnhagem as dúvidas em relação à autoria de Gonzaga das Cartas Chilenas, Sérgio Buarque de Holanda argumenta:

"Dado que seja mais plausível a atribuição a Gonzaga das "Cartas Chilenas" sua leitura ajuda a mudar a nossa idéia tradicional do poeta de Marília, fazendo-a mais exata e familiar. Pode-se dizer que do suave Dirceu tal como as "Liras" o estereotiparam nas imaginações, ao autor sarcástico e azedo, que a sátira anônima deixa adivinhar, vai toda a prodigiosa distância que separa o retrato fantasista de Gonzaga apenso às edições de sua obra e a descrição que do ouvidor de Vila Rica nos transmitiu o Conselheiro Pereira da Silva, fundado aparentemente em honestas tradições.

Como reconhecer nesse homenzinho baixote e prosaicamente gordo aquele perfil de linhas clássicas, emoldurado em longos cabelos ondeantes que se derramam sobre largo busto?"30

Desta passagem me interessa tecer três observações. A primeira diz respeito à constituição narrativa. $\mathrm{O}$ efeito cômico buscado pelo autor ao comparar a imagem que se criou de Gonzaga a partir de padrões estéticos de "gosto arcádico", frente à descrições de época do escritor, criam uma situação na qual a tradição biográfica de Gonzaga é exposta ao ridículo e, deste modo, desmentida. A exploração da dimensão cômica, assim como uma certa dose de ironia ou sarcasmo, bastante comum na obra de Sérgio Buarque, constitui-se no instrumento catalisador da crítica.

Em segundo lugar, é importante ressaltar que por trás dos artifícios discursivos, esta crítica é extremamente focada e visa um objeto real. Conforme vimos anteriormente, a tradição de uma história nacional pressupõe um conjunto de acontecimentos e de personalidades importantes para a nação. No trecho acima, Sérgio Buarque denuncia a existência de duas imagens opostas

\footnotetext{
${ }^{29}$ Sobre a recepção das Cartas nos períodos da 'República Velha' e 'Estado Novo' ver FURTADO, Joaci Pereira. Uma república...op. cit, cap. 4 - 'Espelho' especialmente nas p. 105-140.

${ }^{30}$ HOLANDA, Sérgio Buarque de. Tentativas de mitologia, op. cit., p. 225-6.
} 
de Tomás A. Gonzaga. Uma historicamente verificável através da análise de documentos fidedignos, de um homem "baixote e prosaicamente gordo". Outra ilusória, de um homem de "perfil de linhas clássicas, emoldurado em longos cabelos ondeantes que se derramam sobre largo busto" - uma construção baseada em modelos de representação que remetem à historiografia romântica.

Assim, o crítico sugere ao leitor que a imagem fantasiosa de Gonzaga foi criada num contexto da necessidade de representação de um herói. Não seria demais supor que Sérgio Buarque estivesse referindo-se justamente ao processo de construção dos heróis da Inconfidência Mineira, capítulo fundamental da história comprometida com a construção da identidade nacional.

A terceira e não menos importante observação é que, para Sérgio Buarque, a investigação histórica de quem efetivamente foi Tomás A. Gonzaga é justamente o antídoto para a mitologia que se criou em torno deste autor. Vale ressaltar que o crítico não perde de vista a possibilidade objetiva de se conhecer o passado. No entanto, este exercício não é de forma alguma mecânico e direto, a verdade no exercício das disciplinas da crítica e da história pode ser alcançada desde que se considere que ela é mediada por uma série de complexidades derivadas da distância temporal, espacial, linguiística e material entre o sujeito e o objeto da análise.

Este é um indício interessante da concepção buarqueana de história no final nos anos 1930 e início dos 1940, momento no qual, como já foi tratado neste artigo, Sérgio Buarque de Holanda se constitui como o historiador. Esta constituição não precede nem antecede, mas acompanha e dialoga com o processo de formação do crítico de letras.

Ainda no mesmo artigo, Sérgio Buarque segue argumentando que:

"Em realidade tudo se encontra no poema menos as idéias de subversão que se poderiam esperar. $\mathrm{O}$ autor empenha-se antes em querer ver instaurada a justiça - zelo de magistrado - do que em assistir a uma transformação da sociedade. Sua revolta não é contra as instituições que podem abrigar a injustiça, mas contra a injustiça que deturpa as instituições. Ele se revela aqui o extremo oposto de um revolucionário, pois é precisamente contra o afrouxamento da tradição que se volve quase sempre seu sarcasmo impiedoso." ${ }^{31}$

${ }^{31}$ HOLANDA, Sérgio Buarque de. Tentativas de mitologia, op. cit., p. 226. 
Como se pode perceber, após formular uma crítica áspera à mitologia criada em torno do autor Tomás A. Gonzaga, Sérgio Buarque analisa as idéias contidas no texto das Cartas Chilenas e conclui que elas não contêm idéia subversiva alguma. Muito pelo contrário, estas idéias expressam as concepções de um verdadeiro burocrata colonial no Brasil. Desta forma, o crítico procura desarmar o argumento de que as Cartas Chilenas tenham uma relação direta com as idéias da Inconfidência Mineira.

Vale ressaltar também que este movimento é acompanhado de uma sutil inversão metodológica. A biografia do autor não é pressuposta como condição de possibilidade da existência do texto. O texto é analisado e deste movimento nascem as observações do intérprete que posteriormente pode identificar elementos relacionados a idéias contidas em outros de textos. Um texto é explicado através do outro, de modo que isso se funde em um conjunto submetido a uma identidade, isto é, o desenvolvimento de um pensamento dentro de uma obra. Não seria difícil imaginar que, ao comentar as concepções de direito, estado e tradição em Gonzaga, Sérgio Buarque tivesse em mente outros textos do mesmo autor como, por exemplo, o Tratado de direito natural ${ }^{32}$.

$\mathrm{O}$ crítico segue enumerando os argumentos textuais que fundamentam a idéia de que o futuro inconfidente, Gonzaga, era na realidade um grande conservador. Muitas críticas supostamente feitas por Gonzaga nas Cartas se dirigiam ao crescente desuso de práticas características de estados do Antigo Regime, baseadas na origem divina do poder monárquico e na indivisibilidade do poder temporal e religioso. Nas palavras do crítico:

"Contra os novos costumes, prenúncio da barbárie revolucionária, sua atitude é a de um rigorosista à moda antiga. Indigna-se, por exemplo, porque o governador não cedeu o lado direito ao bispo em uma cerimônia pública..." 33

Além deste exemplo, Sérgio Buarque cita outras críticas do autor das Cartas. Dentre elas, o fato do governador caminhar diante da bandeira do senado e não ao lado desta como reza a tradição, ou o desuso crescente do florete,

\footnotetext{
${ }^{32}$ GONZAGA, Tomás Antônio. Tratado de direito natural. Edição crítica de Manuel Rodrigues Lapa. Rio de Janeiro: Instituto Nacional do Livro, 1957.

${ }^{33}$ HOLANDA, Sérgio Buarque de. Tentativas de mitologia, op. cit.., p. 226.
} 
considerado insígnia de nobreza, uma vez que é uma arma que pode apenas ferir de perto, ao contrário de outras armas consideradas desleais.

De modo geral, as críticas contidas nas Cartas Chilenas ressaltavam a ausência de verdadeiros nobres dentre os administradores coloniais e mesmo sua inobservância aos códigos de nobreza tradicionalmente estabelecidos. Arremata Sérgio:

"Mais do que esses motivos, porém, sente-se que era o desprestígio dos homens de sua categoria o que mais irritava o poeta. Orgulhoso de seu sangue limpo e de sua casta, ele via com maus olhos a jactância de mulatos e de filhos de vendeiros galgando as posições e ganhando consideração. A revolta deste inconfidente era, no fundo, um ressentimento de aristocrata." ${ }^{\prime 34}$

\section{Manuel Bandeira, Sérgio Buarque de Holanda e a constituição de um método crítico}

Como já mencionei ao analisar os textos de Sérgio Buarque, no artigo "A autoria das Cartas Chilenas"35, Manuel Bandeira empreende uma investigação crítica por intermédio de uma comparação de estilos observando a incidência de certas nuances de vocabulário e artifícios de linguagem nas Cartas e no conjunto das obras de seus dois possíveis autores - Tomás A. Gonzaga e Cláudio Manuel da Costa. O resultado da investigação indica que uma série de expressões idiomáticas, vocabulário e figuras de linguagem que aparecem nas Cartas têm incidência muito maior na obra de Gonzaga do que na obra de Cláudio Manuel da Costa.

Em primeiro lugar, merece atenção a atitude deliberada de Bandeira de se esquivar de toda uma tradição de interpretação histórico-literária brasileira que privilegia informações biográficas na explicação de um determinado texto. Por isso o meio pelo qual Manuel Bandeira investiga é o estilo ${ }^{36}$.

\footnotetext{
${ }^{34}$ HOLANDA, Sérgio Buarque de. Tentativas de mitologia, op. cit., p. 229.

${ }^{35}$ BANDEIRA, Manuel, 'A autoria das Cartas Chilenas', Revista do Brasil, ano III, n. 22, p. 1-25, abril de 1940 .

${ }^{36}$ A semelhança entre o método utilizado por Manuel Bandeira para verificar a autoria das Cartas Chilenas e o polêmico método de verificação de autenticidade e autoria de obras de arte (através de pequenos detalhes, como o modo de pintar as unhas, cabelo, em determinado quadro em comparação com outros de mesma autoria, que constituíam o
} 
Em segundo lugar, por trás desta investigação, assim como por trás dos esforços de Sérgio Buarque, existe um profundo compromisso com a obra de cada autor. A identidade no desenvolvimento de idéias e estilo possibilitam a identificação de um conjunto de textos sob o signo de um autor. O método crítico de Manuel Bandeira, bastante inovador sob o ponto de vista do estilo, articula um sistema no qual elementos estilísticos das Cartas, pela incidência que têm na obras de Tomás A. Gonzaga e Cláudio Manuel da Costa, podem ser atribuídos como parte de um ou de outro conjunto. Assim como Sérgio Buarque, Manuel Bandeira parte do texto e tenta compreendê-lo em relação à obra. Quando utilizo a palavra obra, não me refiro, portanto, ao seu sentido unitário - um livro ou texto. Refiro-me ao conjunto de trabalhos que podem ser submetidos a uma identidade, isto é, um autor.

O caráter crítico destes argumentos transparece se levarmos em consideração que o processo de construção da Inconfidência Mineira e das Cartas Chilenas como parte do ideário nacional se intensificou durante o período do Estado Novo, justamente no qual os textos analisados neste artigo foram publicados. O sentido das críticas de Sérgio Buarque de Holanda e Manuel Bandeira é em certa medida político, dirigido contra a construção pelo Estado de uma história ufanista na qual o conflito e as injustiças sociais são encobertas por uma cena semi-edênica de mito constituído de um encadeado de acontecimentos relevantes e homens extraordinários.

Assim, posso dizer que a discussão de Sérgio Buarque e Manuel Bandeira sobre o tema da autoria das Cartas Chilenas não é em si o debate. A discussão entre os dois, que inicialmente me referi com o termo 'debate' é, na realidade, parte de um debate amplo que diz respeito de forma direta às diretrizes culturais do Estado Novo. É possível identificar na postura destes autores uma atitude sediciosa em relação aos ideais de construção e manipulação do discurso histórico, pelo menos entre fins dos anos 1930 e início da década seguinte.

que era o estilo de cada artista), proposto pelo médico italiano Giovanni Morelli em finais do séc. XIX e resgatado pelo historiador italiano Carlo Ginzburg, não é mera coincidência. O paradigma indiciário baseado numa espécie de semiótica que começou a se afirmar nas ciências humanas, principalmente nas décadas de 1870-80, diz respeito também ao ambiente de formação da estilítica alemã de finais do séc. XIX e início do XX, teorias de análise textual que Bandeira direta ou indiretamente se utilizou em uma verificação também sobre a autoria. Cf. Sinais: raízes de um paradigma indiciário. In: GINZBURG, Carlo. Mitos, emblemas, sinais. São Paulo: Cia. das Letras, 2002. 
O debate não se restringe ao que pode ser identificado nas obras de Sérgio Buarque, Bandeira ou Luís Camilo. Muito pelo contrário, sobre este tema e neste período encontraremos apenas concordância nas obras destes autores. O lugar do conflito está para muito além disso, envolve a mobilização e construção de uma história e de uma memória promovida pelo Estado brasileiro em meio a um processo de cristalização do autoritarismo. $\mathrm{O}$ episódio do debate sobre as Cartas Chilenas contribui para esclarecer a instrumentalização da história na solidificação deste ideário nacional.

Nesse sentido, é importante ressaltar o meio de circulação de boa parte do debate, a Revista do Brasil, em sua $3^{\text {a }}$ fase, dirigida por Otávio Tarquínio de Souza, publicada entre 1938 e 1943 e que teve 56 números ${ }^{37}$. Através dela, é possível mapear, como vem fazendo a historiadora Tania Regina de Luca em suas pesquisas ${ }^{38}$, a atividade de um grupo de intelectuais dos quais fazia parte, além de Sérgio Buarque e Manuel Bandeira, Afonso Arinos de Melo Franco e Luís Camilo de Oliveira Neto, Prudente de Moraes Neto, Augusto Meyer, entre outros. Estes intelectuais, ligados à vários órgãos mantidos pelo próprio Estado, como o Instituto Nacional do Livro, a Biblioteca Nacional, Ministério das Relações Exteriores e Casa de Rui Barbosa ${ }^{39}$, formularam alternativas de resistência a seus projetos educativos e construções simbólicas, fundamentados em ideais democráticos e que estão na base de projetos de intervenção política que ganhariam forma mais delineada alguns anos depois.

Além da consonância de opiniões no que diz respeito aos temas discutidos, é possível identificar nos textos de Sérgio Buarque e Manuel Bandeira a utilização de técnicas de análise textual nas quais o estilo e a linguagem figuram como instrumento de crítica, especialmente de crítica histórica. No caso do percurso intelectual de Sérgio Buarque, pode-se identificar em seus artigos

\footnotetext{
${ }^{37}$ LUCA, Tania Regina de. A Revista do Brasil: Um diagnóstico para a (N)ação. São Paulo: Unesp, 1998, p. 31.

${ }^{38}$ LUCA, Tania Regina de. (Re)vistas do Brasil do decorrer do século XX In: LUSTOSA, Isabel. Imprensa, historia e literatura. Rio de Janeiro: Fundação Casa de Rui Barbosa (no prelo). Agradeço a autora pela gentileza de ceder-me o original.

${ }^{39}$ Boa parte destes intelectuais estava ligada a uma espécie de segundo escalão da burocracia estatal brasileira e a tensão entre seu discurso e suas práticas não é absolutamente de se ignorar. Cf. MICELI, Sérgio. Intelectuais e classe dirigente no Brasil (1920-1945). São Paulo/Rio de Janeiro: Difel, 1979. Em especial capítulo 3, "Os intelectuais e o estado".
} 
de crítica literária do período ${ }^{40}$ a recepção e discussão de tendências então emergentes da crítica e teoria literárias, como o new criticism e a estilítica de Leo Spitzer e Eric Auerbach ${ }^{41}$.

Em Bandeira, uma análise dos métodos utilizados em seus textos críticos como os do debate sobre a autoria das Cartas Chilenas, permitiria a identificação do parentesco de alguns elementos de seu instrumental teórico com as mesmas tendências da crítica literária citadas acima. Esta seria uma etapa importante em uma investigação sobre a relação de sua obra crítica com o amadurecimento de sua obra ficcional, em especial poética.

Assim, é possível identificar, durante os anos 1930 e 1940, na obra de Sérgio Buarque de Holanda, e possivelmente também na de Manuel Bandeira, o desenvolvimento de elementos comuns no terreno da crítica literária que participam diretamente do amadurecimento profissional de ambos, seja na produção de história no caso do primeiro, seja na poesia no caso do segundo.

Em um artigo contemporâneo ao debate das Cartas Chilenas, é interessante notar como Sérgio Buarque, ao analisar a obra poética de Manuel Bandeira, identifica alguns destes elementos:

“À medida que assim se apuram, no entanto, as possibilidades técnicas de Bandeira, sua recusa em atender aos padrões bem aceitos evolui para uma impaciência quase agressiva ante certos processos gastos e fáceis. Impaciência que o levará primeiro a estranhas dissonâncias e também à desarticulação metódica de algumas rimas clássicas, e neste caso, realiza, desde 1918 e talvez antes, experiências que um Aragon irá preconizar em 1940, no posfácio ao Crève-Coeur, como caminho de inesperadas

${ }^{40}$ A maioria desses artigos foram publicados nos dois volumes do livro $O$ Espírito e a Letra. Estudos de crítica literária. Organização de Antonio Arnoni Prado. São Paulo: Cia. das Letras.

${ }^{41}$ A referência a estas correntes está concentrada nos artigos que Sérgio Buarque escreveu entre meados dos anos 1940 e início da década seguinte, fundamentalmente nos jornais Diário de Notícias, Diário Carioca, ambos do Rio de Janeiro e Folha da Manhã, de São Paulo (normalmente os artigos publicados nos dois primeiros jornais eram republicados no jornal paulista na semana seguinte). Como exemplo cito os artigos 'O Caso Pound'. Diário Carioca, 19 de novembro de 1950; 'Mimesis'. Diário Carioca, 26 de novembro de 1950 e, séries de artigos como: 'Hermetismo e Crítica' I, II e III, publicada no Diário Carioca nos dias 6, 13 e 22 de maio de 1951; 'Poesia e Positivismo' I, II, III, IV, publicada no Diário Carioca nos dias 22 e 29 de julho, 5 de agosto e 11 de novembro de 1951; e 'Rebelião e Convenção' I e II, publicado nos dias 20 e 27 de abril de 1952 no Diário Carioca. 
riquezas, aos poetas de hoje. Depois, e finalmente, irá até às formas coloquiais e prosaicas e à transgressão voluntária dos preceitos rítmicos e dos preconceitos temáticos longamente consagrados." ${ }^{42}$

Fica patente que o crítico Sérgio Buarque percebe no amigo poeta justamente o que nele é mais profundamente cultivado. A rebelião modernista e, ao mesmo tempo, o domínio técnico e criterioso das convenções, são no poeta e no historiador o instrumento da criação. Ancorados em uma vivência modernista em comum ${ }^{43}$, os estilos e as atividades de Manuel e de Sérgio se metamorfoseiam junto a um novo momento intelectual e político que é no fundo o verdadeiro debate. "E denunciando é justo que a si mesmo denuncie." ${ }^{44}$, como disse o próprio Sérgio Buarque sobre o uso da sátira nas Cartas Chilenas e que pode ser perfeitamente aplicado a seu comentário sobre Bandeira.

Questões como as discutidas acima impulsionam um novo momento na obra de Sérgio Buarque, no qual elementos de sua atividade como crítico literário são incorporadas na investigação de temas de história literária brasileira, em especial dos períodos do barroco e do arcadismo. A intensificação destes interesses pode ser verificada desde a produção da Antologia dos poetas brasileiros da fase colonial, em $1952^{45}$, e a composição de um livro sobre a

\footnotetext{
${ }^{42} \mathrm{O}$ artigo do qual extraí este trecho foi inicialmente editado como 'Poesias Completas de Manuel Bandeira' no Diário de Notícias do Rio de Janeiro a 6 de outubro de 1940 (contido no Espírito e a letra, op. cit., p. 276-282), e posteriormente publicado no mesmo periódico nos dias 5 e 12 de setembro de 1948 (republicado no jornal $O$ Estado de São Paulo nos dia 17 de setembro e 7 de outubro do mesmo ano), sob o título de Trajetória de uma poesia; ganhou sua forma mais conhecida, sob o mesmo título, como prefácio do livro Manuel Bandeira, prosa e poesia (obras completas). Rio de Janeiro: Nova Aguilar, 1958. A versão mais acessível deste artigo foi inclusa pelo autor na segunda edição do livro Cobra de Vidro. São Paulo: Perspectiva, 1979, no qual este trecho encontra-se na p. 42.

${ }^{43}$ É importante lembrar que a relação entre Sérgio Buarque de Holanda e Manuel Bandeira se inicia nos tempos de militância no movimento modernista, principalmente através da colaboração em diversos periódicos e na participação da vida intelectual agitada de São Paulo e do Rio de Janeiro. Radicados no Rio, nenhum dos dois pôde participar da 'Semana de 22', o que implica certo distanciamento em relação ao movimento, acentuado devido à própria dinâmica intelectual do Rio de Janeiro. Este distanciamento não impediu que incorporassem de modo duradouro em suas obras uma adesão às posturas sediciosas e iconoclastas propagadas pelo movimento. Cf. GOMES, Angela de Castro. Essa gente do Rio...Os intelectuais cariocas e o modernismo. Estudos Históricos, Rio de Janeiro, vol. 6, n. 11, 1993, p. 68.

${ }^{44}$ HOLANDA, Sérgio Buarque de. Tentativas de mitologia, op. cit..., p.226.
} 
história da literatura brasileira colonial, entre mais ou menos a data de publicação da Antologia e o início de suas atividades docentes na Universidade de São Paulo, em $1956^{46}$.

Sérgio Buarque nunca chegou a finalizar e publicar este conjunto de textos. Quase 10 anos após sua morte, Antonio Candido os reuniu e publicou sob o título de Capítulos de Literatura Colonial. Nestes textos, é possível identificar o uso de uma série de recursos advindos da experiência de Sérgio como crítico literário ao longo dos anos 1940.

\section{As Novas Cartas Chilenas}

Em 1963, Manuel Bandeira recebeu uma carta enviada do Chile que contém um poema intitulado "Novas Cartas Chilenas". Ela conta com duas epígrafes escritas em um alemão bastante difícil de se compreender, de certo modo, 'macarrônico' - escrito provavelmente por alguém que não é alemão nativo. Ademais o poema contém imprecisões na grafia de palavras e citações que sugerem que elas tenham sido feitas às pressas, sem a ajuda de um dicionário ou mesmo tivessem sido inventadas. Contém também alguns versos escritos em um português cômico, e de vocabulário arcaico. Termina com a inscrição: "Em esta cidade de Santiago do Novo Extremo do Reino do Chile das Índias de Castela, aos 10 dias do mês de dezembro do Ano de Nosso Senhor Jesus Cristo de 1763."

Manuel Bandeira pensou que a brincadeira pudesse ter sido feita por dois de seus amigos que estavam no Chile, ou o poeta Thiago de Melo ou Sérgio Buarque de Holanda. Entretanto, apenas o segundo sabia alemão, o que fez com que Manuel atribuísse a autoria do poema a Sérgio. Como se não bastasse, no ano seguinte o poeta publicou este trabalho, devidamente atribuído ao historiador na segunda edição de sua Antologia dos poetas brasileiros bissextos contemporâneos ${ }^{47}$. Das muitas coisas que pode se dizer deste episódio, talvez o fundamental seja que a questão da autoria volta à tona, desta vez de um modo

\footnotetext{
${ }^{45}$ HOLANDA, Sérgio Buarque de (org.). Antologia dos poetas brasileiros da fase colonial. Rio de Janeiro: Ministério da Educação/Instituto Nacional do Livro, 1952. Vale observar também que outras antologias da mesma coleção, como as das fases romântica e parnasiana, ficaram a cargo de Manuel Bandeira.

${ }^{46}$ CANDIDO, Antonio. Introdução. Capítulos de literatura colonial, op. cit., p. 8-11.

${ }^{47}$ BANDEIRA, Manuel (org). Antologia dos poetas bissextos contemporâneos. Rio de Janeiro: Organizações Simões, 1964.
} 
totalmente cômico e amistoso. O poeta levanta hipóteses sobre a autoria e publica um poema do crítico que tantas vezes o submeteu à análise.

A brincadeira de Sérgio Buarque refere-se a um aspecto fundamental do debate ocorrido mais de 20 anos antes. A questão da autoria não é descartada em nenhum momento por Sérgio Buarque e Manuel Bandeira em seus textos sobre as Cartas Chilenas. Ela é, na realidade, relativizada através de um aparato crítico que substitui explicações do texto através de elementos externos como a própria biografia do autor por uma reflexão que parte do texto para pensálo em contrapartida a outros textos, pertencentes àquela mesma identidade histórica ou identidade autoral. O autor, por sua vez, é concebido como um conceito histórico, o que permite um distanciamento crítico entre a imagem do autor historicamente 'comprovável' e as construções ideológicas posteriores em torno de sua imagem.

Mas será que as Novas Cartas Chilenas são efetivamente de autoria de Sérgio Buarque? E se forem do próprio Manuel Bandeira, ou do fruto da colaboração entre os dois amigos? Assim como nas "velhas" Cartas Chilenas, o que importa na verdade é a intenção deliberada do anonimato. Este pormenor contido em ambas Cartas Chilenas condiciona o sentido do texto, lhe conferindo um tom satírico ou irônico. Ele se constitui em uma rebelião concretizada não na maior parte do texto, em que o autor mobiliza normas e convenções determinadas pelo gosto de uma época, mas nos pequenos detalhes nos quais deixa transparecer sua individualidade - no estilo. A identificação destes traços que constituem-se no estilo depende da consideração de outros trabalhos que parecem se submeter à mesma identidade, ou seja, ao conceito de obra.

Espero que a leitura deste artigo tenha contribuído para o esclarecimento de que a opção pelo estudo de um tema tão caro às correntes mais tradicionais comprometidas com os ideais nacionalistas não é casual. Os esforços de Manuel Bandeira e de Sérgio Buarque soam como uma forma de militância, mas não se trata de qualquer militância. Uma atividade comprometida com projetos de instituição de ciências especializadas, com rigor técnico e honestidade e que, se bem mantidas e aplicadas, poderiam se constituir em uma alternativa à tradições ufanistas comprometidas com ideais políticos conservadores ${ }^{48}$.

\footnotetext{
${ }^{48}$ Mais de uma vez Sergio Buarque mostrou-se otimista com o advento das universidades e das faculdades de filosofia no Brasil e com o processo de especialização das disciplinas da crítica literária e da história. Reproduzo aqui um trecho em que ele se manifesta neste sentido: "Na órbita da política temos visto como ela conduz frequientemente aos falsos heroísmos,
} 
O desenvolvimento do método crítico de Sérgio Buarque de Holanda ainda deve ser muito aprofundado. Neste artigo, tentei mapear questões e encaminhar algumas respostas sobre a formação deste método de investigação histórica nos anos 1940. Seu caráter inicial e incompleto não impediu a tentativa de preservar a historicidade de certos conceitos.

Termos como 'história', 'crítica literária' não podem ser entendidos no sentido atual, de disciplinas acadêmicas autônomas que conhecemos. É necessário levar em consideração que estas disciplinas ainda estavam em processo de formação em meados do século XX no Brasil, impulsionadas pelas atividades das faculdades de filosofia, criadas a partir dos anos 1930, e da sedimentação das pós-graduações e das instituições públicas de fomento à pesquisa. Boa parte deste novo instrumental utilizado no debate analisado neste artigo se relaciona diretamente com este desenvolvimento.

Por fim, devo admitir que este artigo não pôde oferecer uma resposta definitiva sobre a própria questão da autoria das 'novas' e das 'velhas' Cartas Chilenas. A busca da comprovação da autoria de documentos históricos deve continuar gerando longos e virulentos debates, articulando velhos temas e construindo novas tradições. Isto não impedirá que estes debates tenham algo de diferente e inusitado, na medida em que mesmo noções como a de 'autoria' e de 'documento histórico' sofrerão alterações de significado no tempo. Neste artigo, vimos as diversas temporalidades imbricadas na noção de autoria, seja em meados do século XIX, nos anos 1930 e 1940, ou frente aos seus significados atuais. Na mutabilidade destes sentidos pode-se estabelecer nexos para as diversas apropriações que sofrem alguns velhos temas. Assim, mesmo o trabalho analítico do historiador reconfigura a tradição e volta-se aos debates de seu presente.

às falsas disciplinas e às grandezas falsas. O mesmo ocorre de algum modo em outros domínios, e não menos nos da cultura e da arte. À base de qualquer alternativa possível para a liberdade imoderada há de encontrar-se invariavelmente um apelo ostensivo ou implícito à despersonalização(...) Existem também disciplinas intelectuais feitas de modéstia, inquirição metódica e perseverança, que têm sido quase sempre o apanágio ideal do chamado "espírito científico". Até que ponto poderiam incorporar-se a elas os próprios valores da imaginação? Sabemos que no Brasil a deliberação paciente, o trabalho pertinaz e penoso, sem perspectivas de pronto êxito, nunca tiveram suficiente prestígio para se erigirem em virtudes poéticas(...) Nesse ponto ainda caberia uma referência particular à afinidade que existe entre esses novos rumos e a ação que vêm exercendo sobre certas inteligências o método e o ensino universitário, sobretudo o das Faculdades de Filosofia". Missão e profissão, Diário de Notícias, Rio de Janeiro, 22 de agosto de 1948. (Republicado em O espírito e a letra, v. 2, op. cit., p. 39). Também sobre o mesmo tema, 'O pensamento histórico no Brasil durante os últimos cinquienta anos', Correio da Manhã, Rio de Janeiro, 15 de julho de 1951. 